\title{
Vasopressor and Inotrope Use in Canadian Emergency Departments: Evidence Based Consensus Guidelines
}

Dennis Djogovic, MD, FRCPC ${ }^{*}$; Shavaun MacDonald, MD, FRCPC ${ }^{\dagger}$; Andrea Wensel, MD $^{\dagger}$; Rob Green, MD, FRCPC ${ }^{\ddagger \S}$; Osama Loubani, MD, FRCPC ${ }^{\ddagger}$; Patrick Archambault, MD, MSc, FRCPC ${ }^{\text {III"; }}$ Simon Bordeleau, MD"; David Messenger, MD, FRCPC, FCCP**; Adam Szulewski, MD**; Jon Davidow, MDCM, FRCPC ${ }^{* \dagger}$; Janeva Kircher, $\mathrm{MD}^{\dagger}$; Sara Gray, MD, FRCPC, $\mathrm{MPH}^{+\dagger}$; Katherine Smith, $\mathrm{MD}^{\dagger}$; James Lee, $\mathrm{MD}^{\dagger}$; Jean Marc Benoit, MD, CCFP-EM; Dan Howes, MD, FRCPC**

\section{INTRODUCTION}

Patients may present to Emergency Departments (ED) in shock for various reasons. Shock states may be categorized as: cardiogenic, obstructive, distributive or hypovolemic. During initial resuscitation, an emergency medicine physician may also have to transiently deal with undifferentiated shock. While treatment of shock states is primarily aimed at reversing or resolving the cause of shock, emergency medicine physicians may require the use of vasopressors or inotropes to manage these patients. Vasopressors are agents that often act to increase mean arterial pressure by systemic vasoconstriction, while inotropes primarily act to increase cardiac output through a combination of inotropy, chronotropy and afterload reduction. Knowledge regarding which vasopressor or inotrope is most useful in which shock state is essential to the acute care physician, as is knowledge regarding appropriate venous access and potential side effects of the chosen agent. Vasopressor or inotrope use should not supplant rapid institution of definitive treatments for the identified cause of shock.

Current medical literature shows a paucity of evidence based guidelines to help the emergency medicine physician with vasopressor or inotrope use in shock states in the ED. The Critical Care Practice Committee of the Canadian Association of Emergency Physicians (C4) conducted an intensive literature search and guideline development process to help create an evidence based approach for use of these agents in the stabilization of shock.

\section{METHODS}

Clinical need for a set of evidence based recommendations on vasopressor and inotrope use for shock was identified by members of $\mathrm{C} 4$ via informal clinical feedback, lecture and presentation evaluation and feedback and literature review. C4 itself is a heterogeneous group of emergency medicine physicians from across Canada, spanning urban, rural, tertiary and community EDs. Although vasopressor reviews are found in the medical literature, no evidence-based assessments directly relevant to the ED could be found.

Planning for the project occurred from June 2011 to December 2011. The AGREE II (Appraisal of Guidelines for Research and Evaluation II) instrument framework was used to guide project planning. ${ }^{1} \mathrm{C} 4$ members interested in the project formed the Vasopressor and Inotropes in Canadian Emergency department (VICE) subgroup. A set of seven PICO (Population, Intervention, Control, Outcome) clinical questions was established by February 2012. Two section authors were assigned for each question, and a non-voting project chair developed and coordinated the project. As members of the VICE group are spread across Canada, much of the project was

From the *Division of Critical Care Medicine; †Department of Emergency Medicine, University of Alberta, Edmonton, $A B$; $¥ D$ Department of Emergency Medicine; §Department of Anesthesia and Division of Critical Care Medicine, Dalhousie University, Halifax, NS; ףDepartment of Emergency Medicine; "Department of Family Medicine and Division of Critical Care, Université Laval, Québec City, QC; **Department of Emergency Medicine, Queen's University, Kingston, ON; and †+Department of Emergency Medicine and Critical Care Medicine, University of Toronto, Toronto, ON.

Correspondence to: Dennis Djogovic, Room 2-124 Clinical Sciences Building, Edmonton, AB, Canada, T6G 2B7; Telephone: (780) 492-8311; Fax: (780) 492-1500; E-mail: djogovic@ualberta.ca. 
conducted via email and teleconference. No industry funding was required to conduct the project.

A set of group derived, database appropriate keywords was created. The two authors of each section modified and expanded the search strategy to address their own section and performed their own literature review. Section authors were encouraged to search MEDLINE, EMbase, Cochrane Central, Register of Controlled Trials, Cochrane Database of Systematic reviews and the Cochrane Methodology Register and to enlist the help of a librarian or other expert in search strategy. A supplemental search with hand searches of the bibliographies of other literature reviews was also conducted where necessary. Each section author independently reviewed the literature list and identified appropriate studies. Articles identified by both section authors formed a focused literature list, and these articles were retrieved for full text review (Table 1).

The VICE group utilized the GRADE (Grades of Recommendation, Assessment, Development and Evaluation) system to assess and assign quality of evidence, and later to determine strength of recommendations. ${ }^{2-11}$ With use of their focused literature lists, section authors were asked to create recommendations for their assigned topic. Best evidence studies were short listed to identify quality of evidence (Table 1). As per GRADE, quality of evidence was rated A-D ( $\mathrm{A}=$ high quality of evidence, $\mathrm{B}=$ moderate quality of evidence, $\mathrm{C}=$ low quality of evidence, $\mathrm{D}=$ very low quality of evidence). If best identified evidence consisted of randomized controlled trials, rating began as $\mathrm{A}$, and was downgraded to $\mathrm{B}$ if poorly done. If best identified evidence was observational series, then grading began as $\mathrm{C}$ and could be upgraded to $\mathrm{B}$ if well done. Case series and expert opinions were relegated to D level of evidence (Figure A). ${ }^{10,11}$

Once section recommendations were assigned appropriate grading of evidence, the VICE group utilized the Delphi consensus process to determine strength of recommendation. The Delphi technique is a widely used and accepted method of gathering data from participants within their domain of expertise, to bring structure and credibility to consensus-building efforts. ${ }^{12,13}$ GRADE asks

\begin{tabular}{|c|c|c|c|}
\hline Question: & $\begin{array}{l}\text { Literature Search- } \\
\text { number of articles }\end{array}$ & $\begin{array}{c}\text { Focused article list (identified } \\
\text { by both section authors) }\end{array}$ & $\begin{array}{l}\text { Best articles (highest } \\
\text { quality for grading) }\end{array}$ \\
\hline Side effects & 1400 & 109 & 10 \\
\hline Cardiogenic Shock & 95 & 21 & 5 \\
\hline Hypovolemic Shock & 881 & 71 & 8 \\
\hline Obstructive Shock & 1594 & 43 & 10 \\
\hline Distributive Shock & 19122 & 104 & 21 \\
\hline Undifferentiated Shock & 309 & 76 & 6 \\
\hline Vascular Access & 65,129 & 616 & 53 \\
\hline
\end{tabular}

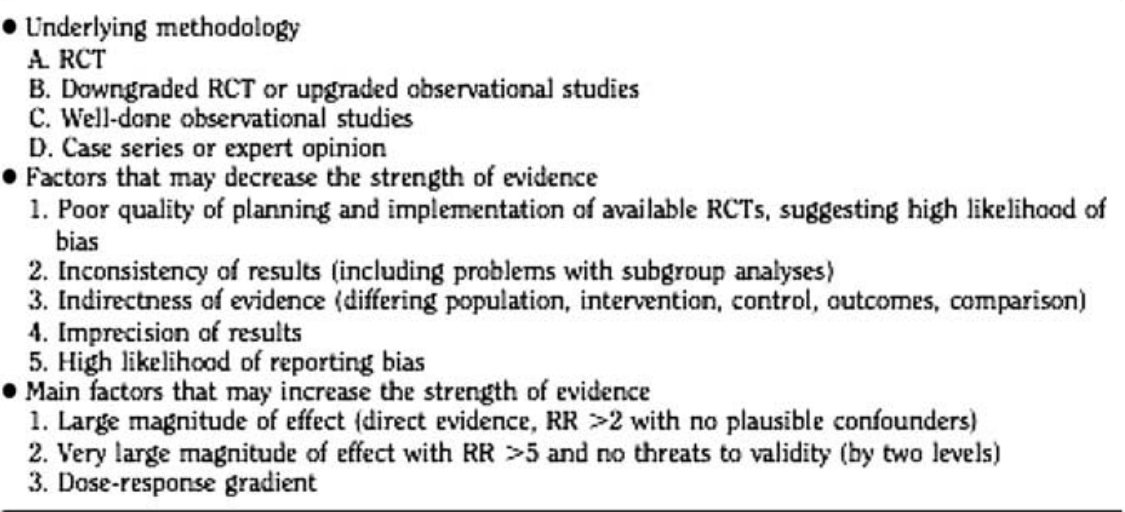

RCT, randomized controlled trial; RR, relative risk.

Crit Care Med 200B; 36:296-327.

Figure A. Determination of quality of evidence using GRADE. 


\begin{tabular}{|c|c|}
\hline \multicolumn{2}{|c|}{ Determinants of strength of recommendation } \\
\hline Factor & Comment \\
\hline $\begin{array}{l}\text { Batance between cesirable and } \\
\text { undesirable effects }\end{array}$ & $\begin{array}{l}\text { The larger the difference between che desirable and undesirable effects, } \\
\text { the higher the likelinood that a strong recommendation is warranted. The } \\
\text { narrower the gradient, the higher the Eikelihood that a weak recommendation is } \\
\text { waranted }\end{array}$ \\
\hline Quality of evidence & $\begin{array}{l}\text { The higher the quality of evidence, the higher the likelinood that a strong } \\
\text { recommendation is warranted }\end{array}$ \\
\hline Values and preferences & $\begin{array}{l}\text { The more values and preferences vary, or the greater the uncertainty in values } \\
\text { and preferences, the higher the Eikelihood that a weak recommendation is } \\
\text { waranted }\end{array}$ \\
\hline Costs (rescurce allocation) & $\begin{array}{l}\text { The higher the costs of an intervention-that is, the greater the rescurces } \\
\text { consumed-the lower the likelihood that a strong recommendation is warranted }\end{array}$ \\
\hline
\end{tabular}

BNJ | 10 MAY 2008 | WOLUME 336

Figure B. Determination of strength of recommendation in GRADE.

\begin{tabular}{|c|c|c|c|c|c|}
\hline & \multicolumn{5}{|c|}{ GRADE score } \\
\hline & 1 & 2 & 0 & 2 & 1 \\
\hline $\begin{array}{l}\text { Balance between } \\
\text { desirable and undesirable } \\
\text { consequences of intervention }\end{array}$ & $\begin{array}{l}\text { Desirable clearty outweigh } \\
\text { undesirable }\end{array}$ & $\begin{array}{l}\text { Desirable probably } \\
\text { Outweigh undesirable }\end{array}$ & $\begin{array}{c}\text { Trade-offs equally balanced } \\
\text { or uncertain }\end{array}$ & $\begin{array}{l}\text { Undesirable probably } \\
\text { outweigh desirable }\end{array}$ & $\begin{array}{l}\text { Undesirable clearly } \\
\text { outweign cesirable }\end{array}$ \\
\hline Recommendation & Strong: "cefinitely do it" & Weak: "probably do it" & $\begin{array}{l}\text { No specific } \\
\text { recommendation }\end{array}$ & $\begin{array}{c}\text { Weak: "probably don't } \\
\text { co it" }\end{array}$ & $\begin{array}{c}\text { Strong: "definitely con"t } \\
\text { do it" }\end{array}$ \\
\hline
\end{tabular}

Figure C. GRADE scoring.

that four main items be considered to determine strength of recommendation: balance between desirable and undesirable effects, quality of evidence, values and preferences, and costs (Figure B). ${ }^{10,11}$ VICE authors voted on each recommendation in order to assign a strength of recommendation rating of "strong" or "conditional" (weak) (Figure C). Seventy percent of votes for "strong" were required for this strength of recommendation to be assigned (Table 2).

\section{RESULTS}

Seven clinical questions were created to address vasopressor and inotrope use in Emergency Departments. Eighteen recommendations were created. Five recommendations were assigned as "strong" recommendations and thirteen recommendations were assigned as "conditional" (Table 3). Once in use, future external validation of the CPG is planned.

\section{Question 1: For ED patients in shock, what are the side effects of vasopressors and inotropes?}

Evidence based statements for side effects of vasopressors and inotropes were created and graded to assist in determining strength (strong versus conditional) of recommendations in other shock questions, but not to become recommendations in and of themselves.

\section{Statement: Dopamine increases the risk of tachyarrhythmia compared to norepinephrine. (Grade A).}

Rationale: A Cochrane review of vasopressor use analyzed six randomized controlled trials comparing dopamine to norepinephrine. ${ }^{14}$ Two studies documented a difference in arrhythmias including sinus tachycardia (25\% versus $6 \%$ ), atrial fibrillation (21\% versus $11 \%)$, ventricular tachycardia (2.4 vs $1.0 \%$ ), and ventricular fibrillation (1.2 vs $0.5 \%$ ). In summary, dopamine produces more arrhythmias (RR 2.34; 95\% CI (1.46, 3.78)). Arrhythmia consequences were not independently identified.

Two other systematic reviews analyzed those same six studies and also concluded significant decrease in arrhythmia with the use of norepinephrine compared to dopamine. ${ }^{15,16}$

\section{Statement: Dopamine use in septic shock increases} mortality compared to norepinephrine (Grade B).

Rationale: The Havel Cochrane review ${ }^{14}$ did not find a significant increase in mortality at 12 months with the 


\begin{tabular}{|c|c|c|c|}
\hline \multicolumn{4}{|c|}{ Table 2. Delphi voting results to determine strength of recommendations } \\
\hline \multirow{19}{*}{ 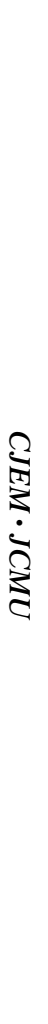 } & Recommendation & $\begin{array}{l}\text { "Strong" } \\
\text { votes }\end{array}$ & $\begin{array}{l}\text { "Conditional" } \\
\text { votes }\end{array}$ \\
\hline & Cardiogenic shock patients in the ED should receive norepinephrine as the first-line vasopressor & 13/13 (100\%) & 0/13 \\
\hline & Cardiogenic shock patients in the ED should receive dobutamine if an inotrope is deemed necessary & $4 / 13(31 \%)$ & $9 / 13$ \\
\hline & Routine vasopressor use in hypovolemic shock is not recommended. & $6 / 13(46 \%)$ & 7/13 \\
\hline & Vasopressin may be indicated in hemorrhagic or hypovolemic shock if a vasopressor is deemed necessary & $0 / 13(0 \%)$ & $13 / 13$ \\
\hline & In obstructive shock not responding to indicated treatment, a systemically active vasopressor should be instituted & $5 / 13(38 \%)$ & $8 / 13$ \\
\hline & $\begin{array}{l}\text { For patients with known or suspected hypertrophic obstructive cardiomyopathy (HOCM) or dynamic outflow obstruction, inotropic agents should be } \\
\text { avoided. Judicious use of vasoconstrictive agents can be considered }\end{array}$ & $1 / 13(8 \%)$ & $12 / 13$ \\
\hline & Norepinephrine is the first line vasopressor for use in septic shock. & $12 / 13(92 \%)$ & $1 / 13$ \\
\hline & Dobutamine should be used for septic shock with low cardiac output despite adequate volume resuscitation & 10/13 (77\%) & $3 / 13$ \\
\hline & $\begin{array}{l}\text { Vasopressin should be considered in catecholamine refractory septic shock. } \\
\text { Vasopressor choice in neurogenic shock is not clear. The agent should be determined by patient characteristics and response to treatment. }\end{array}$ & $6 / 13(46 \%)$ & $7 / 13$ \\
\hline & Norepinephrine is the first line agent for the management of distributive shock due to hepatic failure & $0 / 13(0 \%)$ & $13 / 13$ \\
\hline & Epinephrine infusion is the preferred agent for anaphylactic shock that does not respond to intramuscular or intravenous bolus epinephrine & 10/13 (77\%) & $3 / 13$ \\
\hline & $\begin{array}{l}\text { Vasopressor choice in distributive shock secondary to adrenal insufficiency not responding to steroid replacement is not clear. Patient response to } \\
\text { chosen agents should guide therapy }\end{array}$ & $2 / 13(15 \%)$ & $11 / 13$ \\
\hline & In undifferentiated shock not responding to fluid resuscitation, norepinephrine should be the first-line vasopressor. & $11 / 13(85 \%)$ & $2 / 13$ \\
\hline & In undifferentiated shock, a second vasopressor should be added if a goal MAP $>70 \mathrm{mmHg}$ is not being achieved & $0 / 13(0 \%)$ & 13/13 \\
\hline & $\begin{array}{l}\text { Short term vasopressor infusions ( }<1-2 \text { hours) or boluses via properly positioned and functioning peripheral intravenous catheters are unlikely to } \\
\text { cause local complications }\end{array}$ & $1 / 13(8 \%)$ & $12 / 13$ \\
\hline & Vasopressor infusions for prolonged periods ( $>2-6$ hours) should preferentially be administered via central venous catheters. & $5 / 13(38 \%)$ & $8 / 13$ \\
\hline & $\begin{array}{l}\text { Inotropes can be given via peripheral catheter (short term) or central venous catheters (prolonged period) with a similarly low incidence of local } \\
\text { complications }\end{array}$ & $0 / 13(0 \%)$ & $13 / 13$ \\
\hline & The administration of vasopressors via intra-osseous lines is safe in adults & $0 / 13(0 \%)$ & $13 / 13$ \\
\hline
\end{tabular}




\section{Table 3. Key recommendations summary}

Summary of recommendations for the use of vasopressors and inotropes in the Emergency Department.

\section{Strong Recommendations}

Cardiogenic shock patients in the ED should receive norepinephrine as the first-line vasopressor.

Norepinephrine is the first line vasopressor for use in septic shock.

Dobutamine should be used for septic shock with low cardiac output despite adequate volume resuscitation.

Epinephrine infusion is the preferred agent for anaphylactic shock that does not respond to intramuscular or intravenous bolus epinephrine.

In undifferentiated shock not responding to fluid resuscitation, norepinephrine should be the first-line vasopressor.

\section{Conditional Recommendations:}

Cardiogenic shock patients in the ED should receive dobutamine if an inotrope is deemed necessary.

Routine vasopressor use in hypovolemic shock is not recommended.

Vasopressin may be indicated in hemorrhagic or hypovolemic shock if a vasopressor is deemed necessary.

In obstructive shock not responding to indicated treatment, a systemically active vasopressor should be instituted.

For patients with known or suspected hypertrophic obstructive cardiomyopathy (HOCM) or dynamic outflow obstruction, inotropic agents should be avoided. Judicious use of vasoconstrictive agents can be considered.

Vasopressin should be considered in cathecholamine refractory septic shock.

Vasopressor choice in neurogenic shock is not clear. The agent should be determined by patient characteristics and response to treatment.

Norepinephrine is the first line agent for the management of distributive shock due to hepatic failure.

Vasopressor choice in distributive shock secondary to adrenal insufficiency not responding to steroid replacement is not clear. Patient response to chosen agents should guide therapy In undifferentiated shock, a second vasopressor should be added if a goal MAP> $70 \mathrm{mmHg}$ is not being achieved.

Short term vasopressor infusions (<1-2 hours) or boluses via properly positioned and functioning peripheral intravenous catheters are unlikely to cause local complications.

Vasopressor infusions for prolonged periods (>2-6 hours) should preferentially be administered via central venous catheters.

Inotropes can be given via peripheral catheter (short term) or central venous catheters (prolonged period) with a similarly low incidence of local complications.

The administration of vasopressors via intra-osseous lines is safe in adults. 
use of dopamine compared with norepinephrine in all causes of shock combined. Another systematic review ${ }^{15}$ compared the same studies but with an outcome of mortality at 28 days. They found a decrease in mortality with the use of norepinephrine (RR: 0.91 ; $95 \%$ CI 0.83 to $0.99 ; p=.026$ ) compared to dopamine. A third systematic review ${ }^{16}$ analyzed the previous studies once more, but only included patients in septic shock. One of the included studies had included a mixed population of shock, of which the subgroup of septic shock (1044 of 1659 patients) was extrapolated. ${ }^{17}$ This systematic review found that dopamine increased mortality at 28 days (RR $1.12 ; 95 \%$ CI $1.01-1.20 ; p=.035$ ). It also assessed six observational studies in septic shock and dopamine again increased mortality at 28 days (RR, 1.23 ; $95 \%$ CI $1.05-1.43 ; p<.01)$.

Statement: Vasopressin as a first line vasopressor may be associated with cellular ischemia and skin necrosis, particularly when combined with sustained moderate to high dose infusions of norepinephrine. (Grade C).

Rationale: One study in septic shock ${ }^{18}$ demonstrated ischemia of the mesenteric mucosa, skin, and myocardium with vasopressin use. Elevated hepatic transaminase and bilirubin concentrations, hyponatremia and thrombocytopenia were also reported. A retrospective review of all patients who received vasopressin at a tertiary care adult regional burn centre demonstrated that vasopressin in combination with high dose norepinephrine is associated with intestinal necrosis, peripheral ischemia, skin graft failure, and donor site conversion. ${ }^{19}$ Limiting the dosage to $0.03 \mathrm{U} /$ minute or less may minimize the development of these adverse effects.

\section{Statement: Epinephrine increases metabolic abnormalities compared to norepinephrine. (Grade A).}

Rationale: A prospective, double-blind, randomizedcontrolled trial of norepinephrine versus epinephrine in achieving mean arterial pressure in ICU patients ${ }^{20}$ found that epinephrine was associated with the development of significant but transient metabolic effects (tachycardia, lactic acidosis, insulin requirements) that prompted the withdrawal of 18/139 (12.9\%) patients from the study by attending clinicians. There was no difference in 28 and 90-day mortality.
Statement: Epinephrine increases metabolic abnormalities compared to norepinephrinedobutamine in cardiogenic shock without acute cardiac ischemia. (Grade B).

Rationale: A small, open, randomized interventional study $^{21}$ evaluated two different therapies in acute heart failure without evidence of acute cardiac ischemia (epinephrine alone versus norepinephrine and dobutamine). Treatment with epinephrine is associated with a transient lactic acidosis, tachycardia, higher incident of arrhythmia, and inadequate gastric mucosa perfusion. No difference in mortality was observed.

\section{Question 2: Which vasopressors and inotropes should be used in the treatment of ED patients with cardiogenic shock?}

Recommendation: Cardiogenic shock patients in the ED should receive norepinephrine as the firstline vasopressor. (Strong)

Rationale: A large, high-quality, multicenter, randomized trial compared norepinephrine to dopamine as first-line vasopressor therapy for patients presenting in shock. While no difference in mortality was found between groups overall, the planned subgroup analysis of patients presenting in cardiogenic shock demonstrated that use of dopamine was associated with a significantly higher 28-day mortality. ${ }^{17}$ There was also a higher incidence of arrhythmia in the dopamine group overall. However, a recent Cochrane review of vasopressors for hypotensive shock $^{14}$ suggests that, because randomization in the DeBacker ${ }^{17}$ study was not stratified by shock type, there is a possibility that the mortality difference in the cardiogenic shock subgroup could be due to chance. Yet, other evidence does exist to support the notion that dopamine may be a sub-optimal choice of vasopressor in cardiogenic shock. An analysis of a large, multi-center prospective observational cohort study, ${ }^{22}$ suggests that dopamine use may be associated with a higher mortality in shock of all etiologies. This further supports the evidence in favour of norepinephrine.

Recommendation: Cardiogenic shock patients in the ED should receive dobutamine if an inotrope is deemed necessary. (Conditional)

Rationale: One small, open-label randomized trial of 30 patients $^{21}$ compared a combination therapy of titrated 
norepinephrine and fixed-dose dobutamine versus monotherapy of titrated epinephrine in patients with cardiogenic shock without evidence of acute cardiac ischemia. This trial demonstrated equal efficacy on global hemodynamics between the two regimens, but patients treated with epinephrine had higher lactate levels, higher heart rates, higher incidence of arrhythmias, and evidence of inadequate gastric mucosa perfusion, suggesting that the combination therapy might be preferable. Patients with active ischemia were excluded, and this group is responsible for the vast majority of cardiogenic shock encountered in the ED. The DeBacker trial, ${ }^{17}$ and an analysis from a large multi-center prospective observational cohort study ${ }^{22}$ both provide evidence that dopamine use may be associated with higher mortality in shock of all etiologies, hence its use as first-line inotropic therapy is not recommended. The quality of the literature that directly compares dopamine with dobutamine is not particularly strong, and is largely performed in the context of severe heart failure patients, not specifically in cardiogenic shock. One small randomized crossover study of 13 patients compared hemodynamic variables in patients with acute cardiogenic circulatory collapse treated with dopamine vs dobutamine as single agent therapy, ${ }^{23}$ and found that dobutamine improved stroke index and cardiac index significantly more than did dopamine, while dopamine increased LV filling pressure more than dobutamine.

Question 3: Which vasopressors and inotropes should be used in the treatment of ED patients with hypovolemic shock?

\section{Recommendation: Routine vasopressor use in hypovolemic shock is not recommended. (Conditional)}

Rationale: The use of any vasopressor in the treatment of hemorrhagic shock in humans has been evaluated thus far in scattered case reports, four medical record reviews, one prospective cohort study, and one RCT. $^{24-31}$ Two negative studies ${ }^{25,31}$ have shown an association with increased mortality in patients who received vasopressors, but the remaining studies show positive outcomes with respect to survival. Most studies involved the use of vasopressin ${ }^{24,25,27,29,30}$ (see next section). Further study into the indications for vasopressor use in hemorrhagic or hypovolemic shock, and the preferred agent, are required.
Recommendation: Vasopressin may be indicated in hemorrhagic or hypovolemic shock if a vasopressor is deemed necessary. (Conditional)

Rationale: Promising studies of hemorrhagic shock in animal models have shown vasopressin improves organ perfusion and survival. In humans, there are three $\operatorname{cases}^{27,29}$ of vasopressin use leading to return of spontaneous circulation or resolution of shock in patients with hemorrhagic shock unresponsive to fluids or catecholamines. Vasopressin has also been studied in a chart review and a weak RCT showing some benefit. $^{24,30}$ However, Collier et $\mathrm{al}^{25}$ showed that the use of vasopressin was associated with increased mortality in their retrospective cohort analysis. A multi-centre RCT is currently in progress to assess the rate of admission to hospital, fluid requirements, hemodynamic variables, and rate of discharge in a population of traumatic refractory hemorrhagic shock patients treated with vasopressin or placebo. ${ }^{32}$

\section{Question 4: Which vasopressors and inotropes should be used in ED patients with obstructive shock?}

\section{Recommendation: In obstructive shock not responding to indicated treatment, a systemically active vasopressor should be instituted. (Conditional)}

Rationale: Evidence to elucidate vasopressor or inotrope use in obstructive shock is limited to case reports, case series and chart reviews. Case reports and case series related to massive pulmonary embolism have utilized various agents such as dopamine, norepinephrine, epinephrine, levosimendan and dobutamine, without the ability to make strong suggestions for care. ${ }^{33-35}$ The largest study is an observational review of 87 patients with pulmonary embolism in whom the use of norepinephrine or epinephrine was associated with worse ICU outcome, but no alternatives to treatment of the obstructive shock are offered. ${ }^{36}$ Studies addressing cardiac tamponade are also not able to offer strong treatment suggestions. ${ }^{37,38}$ Physiologically it is reasonable to use vasopressors temporarily for the obstructive shock patient to preserve cerebral and cardiac perfusion until definitive treatment is instituted. Definitive treatment should be implemented emergently for obstructive shock patients. 
Recommendation: For patients with known or suspected hypertrophic obstructive cardiomyopathy (HOCM) or dynamic outflow obstruction, inotropic agents should be avoided. Judicious use of vasoconstrictive agents can be considered. (Conditional)

Rationale: Only a series of three case reports could be found to specifically address this issue. One case reported decompensation of a patient intraoperatively after ephedrine administration, ${ }^{39}$ another case described cardiovascular collapse after a dopamine/norepinephrine combination $^{40}$ and one case reported successful use of phenylephrine during caesarean section. ${ }^{41}$ Physiologically, it would seem reasonable to avoid the afterload reducing effects of inotropes in these fixed cardiac output states. If decompensation and mortality are imminent, it would seem physiologically sound to consider vasopressor support.

\section{Question 5: Which vasopressors and inotropes should be used in ED patients with distributive shock?}

Due to the numerous conditions that can cause distributive shock, independent sections and recommendations were created for septic shock, neurogenic shock, hepatic failure, anaphylactic shock, and adrenal insufficiency.

\section{Recommendations: Norepinephrine is the first line vasopressor for use in septic shock.} (Strong)

Rationale: Norepinephrine, epinephrine, phenylephrine, dopamine and vasopressin can all increase blood pressure in patients with septic shock. ${ }^{14}$ Older guidelines and reviews suggest that either norepinephrine or dopamine should be used as the first line vasopressor for septic shock. ${ }^{42-45}$ The 2012 Surviving Sepsis Guidelines suggest using norepinephrine as the first line agent for these patients. ${ }^{46}$

Norepinephrine vs Dopamine. There are two recent large randomized controlled trials (RCTs) comparing mortality in patients with shock who were treated with dopamine or norepinephrine. ${ }^{17,47}$ One of the RCTs included only patients with septic shock, while the other included patients with all types of shock. The RCT with only septic shock patients demonstrated a mortality benefit in favor of norepinephrine. ${ }^{48}$ In contrast, a recent large cohort study suggested higher mortality in patients treated with norepinephrine. This is contrasted by observational studies that demonstrated higher mortality in patients with septic shock who were treated with dopamine. ${ }^{22,49}$ With respect to morbidity, the use of dopamine has been associated with an increased risk of dysrhythmias. ${ }^{14,16}$ There are two recent systematic reviews ${ }^{15,50}$ and a meta-analysis ${ }^{16}$ that compare dopamine to norepinephrine. Two of the three concluded that norepinephrine confers a mortality benefit. All three demonstrated an increased risk of cardiac dysrhythmias when dopamine is used.

Epinephrine. The role of epinephrine in patients with septic shock is unclear. Although studies such as those by Seguin et $\mathrm{al}^{51}$ and Levy et $\mathrm{al}^{52}$ have shown a difference in hemodynamic parameters and measures of tissue perfusion, two RCTs comparing norepinephrine (+ dobutamine where indicated) to epinephrine did not show a difference in mortality. ${ }^{20,53}$ The 2012 Surviving Sepsis Guidelines recommend the addition of epinephrine to norepinephrine "when [an] additional agent is needed to maintain adequate blood pressure". ${ }^{46}$ Mahmoud et $\mathrm{al}^{54}$ compared dobutamine to epinephrine for cardiovascular support in patients with septic shock who were already being treated with norepinephrine. This study did not show a difference in mortality between the groups. Serum lactate levels and $\mathrm{pH}$ were worse in the epinephrine group.

Phenylephrine. The pharmacologic properties of phenylephrine make it a less appealing choice during the setting of septic shock. There are trials comparing phenylephrine to norepinephrine in terms of hemodynamic and metabolic parameters showing equivalence $^{55,56}$ or inferiority ${ }^{57}$ to norepinephrine. A 2011 review by Thiele et al discusses the evidence for the use of phenylephrine, including special situations where it might be the preferred agent. ${ }^{58}$ Phenylephrine is not recommended for routine use in patients with septic shock. ${ }^{46}$

Methylene Blue. Methylene blue can be administered as a bolus or an infusion. No studies have demonstrated a survival benefit with methylene blue. Methylene blue has been associated with positive physiologic effects such as increased MAP and SVR and reduced requirements for other vasopressors. ${ }^{64-67}$ Methylene 
blue can be considered for salvage therapy in septic shock refractory to fluids, catecholamines, and vasopressin.

\section{Recommendation: Vasopressin should be considered in catecholamine refractory septic shock. (Conditional)}

Rationale: The role of vasopressin in septic shock is unclear. Some patients with septic shock are vasopressin deficient but the clinical importance of this is unknown. When compared to norepinephrine as a first line agent for septic shock, vasopressin did not achieve MAP targets and rescue norepinephrine was required. ${ }^{59}$ Vasopressin has been shown to reduce the dose of catecholamines required to achieve MAP targets in patients with septic shock. ${ }^{60}$ The VASST study did not demonstrate a survival benefit when a vasopressin infusion was added to patients with septic shock who were already being treated with at least $5 \mathrm{mcg} / \mathrm{min}$ of norepinephrine. ${ }^{61}$ Subgroup analysis of this study suggested that patients who were on lower doses of norepinephrine when vasopressin was initiated might have better survival. A later study by Oliveira et al (2011) demonstrated a reduction in 14 and 28 day mortality when patients were started on vasopressin in the setting of low dose norepinephrine (approx. 3.5-10 $\mathrm{mcg} / \mathrm{min}){ }^{62}$ In 2008, Lam and Bauer demonstrated similar results. ${ }^{63}$

\section{Recommendation: Dobutamine should be used for septic shock with low cardiac output despite adequate volume resuscitation. (Strong)}

Rationale: Cardiac dysfunction (septic cardiomyopathy) is common in septic patients. The presence of low cardiac index and the need for inotropes has been associated with increased 90-day mortality in patients with septic shock. ${ }^{68}$ Earlier studies demonstrated that dobutamine improved cardiac index as well as creatinine clearance and gastric microcirculation. ${ }^{51,69,70}$ More recent studies on the use of dobutamine in septic shock also demonstrated an improvement in cardiovascular parameters, but only limited improvement in microcirculation. ${ }^{71-73}$ Dobutamine was included in Rivers' study of early goal directed therapy. ${ }^{74}$ Dobutamine is recommended in the 2012 Surviving Sepsis Guidelines for patients who demonstrate low cardiac output despite volume resuscitation. ${ }^{46}$
Recommendation: Vasopressor choice in neurogenic shock is not clear. The agent should be determined by patient characteristics and response to treatment. (Conditional)

Rationale: There are no studies comparing agents for the management of hypotension due to neurogenic shock. Several reviews suggest that, based on physiology, agents with beta agonist effects, such as dopamine, may be preferred over those with only alpha effects such as phenylephrine. We are not addressing the use of vasopressors to achieve supra-normal blood pressure following spinal cord injury in order to attempt to reduce the severity of injury. We have, however, included a review by Ploumis et al that looked at the ability of various agents to achieve supra-normal BP, and did not identify a difference between them. ${ }^{75}$ If these agents all effectively achieve supra-normal BP, it seems reasonable to expect that they would also achieve a 'normal' BP target and thus would be effective for the management of hypotension due to neurogenic shock. Given the lack of evidence, the choice of agent used is determined by patient characteristics and response to treatment.

Recommendation: Norepinephrine is the first line agent for the management of distributive shock due to hepatic failure. (Conditional)

Rationale: There are no studies comparing vasopressor agents in patients with distributive shock due to hepatic failure. Recent reviews and guidelines suggest norepinephrine as a first line therapy based on a physiologic rationale. ${ }^{76-83}$ The role of vasopressin in patients with hepatic failure is also unknown, but may be considered as a 2nd line agent for distributive shock due to liver failure that is not responsive to norepinephrine. ${ }^{79,84}$ There is physiologic evidence to support the use of vasopressin to improve MAP in these patients. ${ }^{85}$

Recommendation: Epinephrine infusion is the preferred agent for anaphylactic shock that does not respond to intramuscular or intravenous bolus epinephrine. (Strong)

Rationale: There are no randomized studies looking at the use of epinephrine for anaphylactic shock in humans. A recent Cochrane review on the use of epinephrine for the treatment of anaphylaxis did not find any studies suitable for analysis. ${ }^{86}$ A cohort study that analyzed the safety of an epinephrine infusion in 
patients with anaphylactic shock did not demonstrate any significant adverse effects. ${ }^{87}$ Studies in animals have demonstrated potential benefit with the use of phenylephrine, norepinephrine, vasopressin and methylene blue in animal models of anaphylactic shock. ${ }^{88-90}$ There are multiple case reports describing the use of vasopressin, norepinephrine and methylene blue in patients with anaphylaxis refractory to epinephrine..$^{91-101}$ Consensus guidelines recommend the use of an epinephrine infusion if a vasopressor infusion is required for patients with anaphylactic shock. ${ }^{102-107}$

Recommendation: Vasopressor choice in distributive shock secondary to adrenal insufficiency not responding to steroid replacement is not clear. Patient response to chosen agents should guide therapy. (Conditional)

Rationale: There are no human trials comparing vasopressors in the setting of adrenal insufficiency. Steroid replacement needs to be instituted as soon as possible. Human case reports of adrenal insufficiency frequently describe reduced responsiveness to catecholamines. No recommendations for the use of a particular vasopressor can be made in these patients. ${ }^{108-110}$ Several studies demonstrated vasopressin insufficiency in patients with septic shock and laboratory diagnosed adrenal insufficiency; however, there are no trials demonstrating that vasopressin provides a survival advantage in this group. ${ }^{59-63}$

\section{Question 6: Which vasopressors and inotropes should be used in ED patients with undifferentiated shock?}

Recommendation: In undifferentiated shock not responding to fluid resuscitation, norepinephrine should be the first-line vasopressor. (Strong)

Rationale: A large, multicenter, double-blinded randomized controlled trial showed equivalence between norepinephrine and dopamine in patients with shock; however, dopamine was associated with an increased rate of arrhythmias and a significantly increased rate of death in cardiogenic shock. ${ }^{17}$ Additionally, a large, multicenter, observational cohort study showed that dopamine was associated with increased mortality rates and that dopamine was an independent risk factor for ICU mortality in patients with shock of any cause. ${ }^{22}$
Another large, multicenter, double-blinded randomized controlled trial showed equivalence between norepinephrine and epinephrine; however, epinephrine was associated with adverse metabolic effects, such as lactic acidosis, tachycardia, and increased insulin requirements. ${ }^{20}$ Lastly, a recent Cochrane Review on vasopressors for shock ${ }^{14}$ concluded that there was not sufficient evidence to prove that any of the vasopressors were superior to others; however, dopamine appears to increase the risk for arrhythmias. While the ability to demonstrate mortality benefit for a particular vasopressor in undifferentiated shock is unclear, norepinephrine will have less adverse effects during use as compared to other vasopressors.

Recommendation: In undifferentiated shock, a second vasopressor should be added if a goal $M A P>70 \mathrm{mmHg}$ is not being achieved. (Conditional)

Rationale: Observational trends from a large, multicenter, double-blinded randomized controlled trial and a large, multicenter, observational cohort study report the addition of a second vasopressor agent in up to $26 \%{ }^{18}$ and $54 \%{ }^{22}$ of cases in all shock types. If other treatment principles are being addressed and the mean arterial pressure goal is still not being met, then the addition of a second vasopressor may be required. Evidence is not strong enough to recommend a particular agent.

\section{Question 7: How should vasopressors and inotropes be administered to ED patients?}

Recommendation: Short term vasopressor infusions (<1-2 hours) or boluses via properly positioned and functioning peripheral intravenous catheters are unlikely to cause local complications. (Conditional)

\section{Recommendation: Vasopressor infusions for prolonged periods (>2-6 hours) should preferentially be administered via central venous catheters. (Conditional)}

Rationale: 51 papers were identified in the literature from 1940-2012 describing 200 cases of local complications from vasopressor administration..$^{61,111-162}$ Vasopressors were administered peripherally in 196 of these cases $^{111-113,115-158,160-162}$, and centrally in four. ${ }^{61,114,159}$ 
The following observations regarding cases where peripherally administered vasopressors resulted in local complications can be made:

Extravasation with no skin/tissue complications occurred in 66 cases, extravasation with skin/tissue necrosis occurred in 20 cases, and skin/tissue necrosis with no extravasation occurred in 110 .

Patients with short infusions of vasopressor medications had few complications. Only 1 case $(<1 \%)$ of skin necrosis occurred $<1$ hour after peripheral vasopressor administration; $89.4 \%$ of reported complications occurred when vasopressor was administered peripherally for $>6$ hours. Recognizing the limitations of relying on case series and case reports, this data indicates that complications from peripheral administration of vasopressors tend to occur with prolonged infusions.

Complications occurred more commonly when administered in distal sites. $86 \%$ of cases with complications when peripheral intravenous site was located in distal extremities (hand, wrist, forearm, saphenous vein, foot). Only $14 \%$ of complications occurred when vasopressor was administered in proximal sites (antecubital fossa, external jugular vein, thigh).

There were four cases reported of local complications from vasopressor administration via central lines. ${ }^{61,114,159}$ Extravasation with no skin necrosis occurred in two cases, and skin necrosis with no extravasation occurred in two cases. Site of administration was internal jugular in one case and femoral in another (other articles did not report site). The duration of vasopressor infusion was between 6-120 hours. Recognizing the limitations of relying on case series and case reports, this data indicates that there is a relatively low rate of local complications from central administration of vasopressors.

\section{Recommendation: Inotropes can be given via peripheral catheter (short term) or central venous catheters (prolonged period) with a similarly low incidence of local complications. (Conditional)}

Rationale: This recommendation is based on three papers, ${ }^{116,120,140}$ all of which were case series or case reports. Five reports of complications local to site administration were described; three from central administration ${ }^{120}$ and two from peripheral administration. ${ }^{116,140}$ These complications included four cases of skin/tissue necrosis and one of extravasation with no tissue damage, and occurred with administration lasting between 16-864 hours. Given the low incidence of reported cases of local complications from either central or peripheral administration, it is reasonable to conclude that inotrope administration either peripherally or centrally is safe.

\section{Recommendation: The administration of vasopressors via intra-osseous lines is safe in adults. (Conditional)}

Rationale: While there are papers evaluating speed and general safety of intra-osseous catheters for vascular access, no reports were found specifically describing safety or local complications from intra-osseous infusion of vasopressors in adults. There are three case reports of local complications in children (compartment syndrome, tissue necrosis, osteomyelitis. ${ }^{163-165}$ However, these occurred in very young children (6 years, 7 month, 3 months) receiving large resuscitative doses of vasopressors, and are not clearly relevant to adults. Given that the intra-osseous compartment is considered a non-compressible central vein, it seems reasonable to conclude that intra-osseous administration of vasopressors may yield a low incidence of complications from the vasopressor itself.

\section{CONCLUSIONS}

Vasopressor and inotrope use in the Emergency Department for patients in shock is necessary and commonly prescribed. Definitive treatments must not be delayed nor forgotten if using vasopressors or inotropes. These evidence based guidelines are intended to help guide the Emergency Medicine practitioner to the most effective and safest utilization of these medications. A user-friendly algorithm poster for implementation in Canadian EDs is attached (see powerpoint poster slide Appendix 1). Hopefully, ongoing research trials will provide future high level evidence with which to edit and advance these guidelines.

Competing interests: No authors have submitted a financial nor conflict of interest relating to the submission of this manuscript

\section{SUPPLEMENTARY MATERIAL}

To view supplementary material for this article, please visit http://dx.doi.org/10.1017/cem.2014.77 


\section{REFERENCES}

1. The AGREE Collaboration. (2003). Development and validation of an international appraisal instrument for assessing the quality of clinical practice guidelines: The AGREE project. Quality and Safety in Health Care, vol. 12, 18-23. doi: 10.1136/qhc.12.1.18.

2. Atkins D, Eccles M, Flottorp S, et al. Systems for grading the quality of evidence and the strength of recommendations I: critical appraisal of existing approaches. The GRADE Working Group. BMC Health Serv Res 2004;4(1):38.

3. Guyatt G, Oxman A, Vist G, et al. GRADE: an emerging consensus on rating quality of evidence and strength of recommendations. BMF 2008;336:924-6.

4. Jaeschke R, Guyatt GH, Dellinger P, et al. Use of GRADE grid to reach decisions on clinical practice guidelines when consensus is elusive. BM7 2008;337:a744:327-30.

5. Guyatt GH, Oxman AD, Kunz R, et al. What is "quality of evidence" and why is it important to clinicians? BMF 2008;336:995-8.

6. Guyatt GH, Oxman AD, Kunz R, et al. Going from evidence to recommendations. BM7 2008;336:1049-51.

7. Schünemann HJ, Oxman AD, Brozek J, et al. Grading the quality of evidence and strength of recommendations for diagnostic tests and strategies. BMF 2008;336:1106-10.

8. Guyatt GH, Oxman AD, Kunz R, et al. Incorporating considerations of resources use into grading recommendations. BM7 2008;336:1170-3.

9. Dellinger RP, Levy MM, Carlet JM, et al. Surviving sepsis campaign: international guidelines for management of severe sepsis and septic shock: 2008. Crit Care Med 2008;36:296-327.

10. GRADE working group. Grading quality of evidence and strength of recommendations. BMF 2004;328:1490-8.

11. Guyatt G, Gutterman D, Baumann MH, et al. Grading strength of recommendations and quality of evidence in clinical guide- lines: Report from an American College of Chest Physicians task force. Chest 2006;129:174-81.

12. Graham B, Regehr G, Wright J. Delphi as a method to establish consensus for diagnostic criteria. 7 of Clinic Epi 2003;56:1150-6.

13. Hsu CC, Sandford BA. The Delphi Technique: Making Sense of Consensus. Practical Assessment, Research and Evaluation 2007;12(10):ISSN 1531-7714.

14. Havel C, Arrich J, Losert H, et al. Vasopressors for hypotensive shock (Review). Cochrane Database of Systematic Reviews 2011, Issue 5.

15. Vasu TS, Cavallazzi R, Hirani A, et al. Norepinephrine or Dopamine for Septic Shock: Systematic Review of Randomized Clinical Trials. 7 Intensive Care Med 2012;27: 172-178.

16. De Backer D, Aldecoa C, Nijmi H, et al. Dopamine versus norepinephrine in the treatment of septic shock: A metaanalysis. Crit Care Med 2012;40(3):725-30.

17. De Backer D, Biston P, Devriendt J, et al. Comparison of Dopamine and Norepinephrine in the Treatment of Shock. NE7M 2010;362:779-89.

18. Obritsch MD, Jung R, Fish DN, et al. Effects of continuous vasopressin infusion in patients with septic shock. Ann Pharmacother 2004;38:1117-22.
19. Cartotto R, McGibney K, Smith T, et al. Vasopressin for the septic burn patient. Burns 2007;33(4):441-51.

20. Myburgh JA, Higgins A, Jovanovska A, et al. A comparison of epinephrine and norepinephrine in critically ill patients. Intensive Care Med 2008;34(12):2226-34.

21. Levy B, Perez P, Perny J, et al. Comparison of norepinephrine-dobutamine to epinephrine for hemodynamics, lactate metabolism, and organ function variables in cardiogenic shock. A prospective, randomized pilot study. Crit Care Med 2011;39:450-5.

22. Sakr Y, Reinhart K, Vincent JL, et al. Does dopamine administration in shock influence outcome? Results of the Sepsis Occurrence in Acutely Ill Patients (SOAP) Study. Crit Care Med 2006;34:589-97.

23. Francis GS, Sharma B, Hodges M. Comparative hemodynamic effects of dopamine and dobutamine in patients with acute cardiogenic circulatory collapse. Am Heart $\mathcal{J}$ 1982;103:995-1000.

24. Cohn SM, McCarthy J, Stewart RM, et al. Impact of lowdose vasopressin on trauma outcome: prospective randomized study. World 7 of Surg 2011;35(2):430-9.

25. Collier B, Dossett L, Mann M, et al. Vasopressin use is associated with death in acute trauma patients with shock. 7 of Crit Care 2010;25(173):e9-14.

26. Fangio P, Asehnoune K, Edouard A, et al. Early embolization and vasopressor administration for management of life-threatening hemorrhage from pelvic fracture. $\mathcal{7}$ of Trauma - Injury, Infection and Crit Care 2005;58(5): 978-984.

27. Haas T, Voelckel WG, Wiedermann F, et al. Successful resuscitation of a traumatic cardiac arrest victim in hemorrhagic shock with vasopressin: A case report and brief review of the literature. $\mathcal{F}$ of Trauma - Injury, Infection and Crit Care 2004;57:177-9.

28. Plurad DS, Talving P, Lam L, et al. Early vasopressor use in critical injury is associated with mortality independent from volume status. 7 of Trauma - Injury, Infection and Crit Care 2011;71(3):565-72.

29. Sharma RM, Setlur R. Vasopressin in hemorrhagic shock. Anesthesia \& Analgesia 2005;101:833-4.

30. Shelly MP, Greatorex R, Calne RY, et al. The physiological effects of vasopressin when used to control intra-abdominal bleeding. Intensive Care Med 1988: 526-31.

31. Sperry JL, Minei JP, Frankel HL, et al. Early use of vasopressors after injury: Caution before constriction. $\mathcal{F}$ of Trauma - Injury, Infection and Crit Care 2008;64:9-14.

32. Wenzel V, et al. A Multicenter, Randomized, Controlled Trial Assessing Arginine Vasopressin Versus Saline Placebo in Refractory Traumatic Hemorrhagic Shock Patients (VITRIS-Study). Available at: http://clinicaltrials.gov/ct2/ show/NCT00379522? term =vitris\&rank $=1$.

33. Boulain T, Lanotte R, Legras A, et al. Efficacy of epinephrine therapy in shock complicating pulmonary embolism. Chest 1993;104:300-2.

34. Powell B P, Simes D. Levosimendan in acute pulmonary embolism. Anesthesia and Intensive Care 2007;35(5):771-2.

35. Jardin F, Genevray B, Brun-Ney D, Margairaz A. Dobutamine: a hemodynamic evaluation in pulmonary embolism shock. Crit Care Med 1985;13(12):1009-12. 
36. Bahloul M, Chaari A, Kallel H, et al. Pulmonary Embolism in intensive care unit: predictive factors, clinical manifestations and outcome. Ann of Thoracic Med 2010;5(2):97-103.

37. Hata $M$, Sezai A, Iida $M$, et al. A non-operative survival case of an 84 year old patient with type A acute aortic dissection complicated by pulseless tamponade. Annals of Thoracic Cardiovascular Surgery 2006;12(4):297-9.

38. Kim R, Siouffi S, Silberstein TA, et al. Management and clinical outcomes of acute cardiac tamponade complicating electrophysiologic procedures: A single-center case series. Pacing and Clinical Electrophysiology 2009; Jun 33:667-74.

39. Schmitto JD, Hein S, Brauer A, et al. Perioperative myocardial infarction after cesarean section in a young woman with hypertrophic obstructive cardiomyopathy. Acta Anaesthesiologica scandinavica 2008;52(4):578-9.

40. Auer J, Berent R, Weber T, et al. Catecholamine therapy inducing dynamic left ventricular outflow tract obstruction. Int 7 of Cardiology 2005;101:325-8.

41. Deimi R, Hess W, Bahlmann E. Primary cesarean section. Use of phenylephrine during anesthesia in a patient with hypertrophic cardiomyopathy. Der Anaesthesist 2000;4(6):1-5.

42. Beale RJ, Hollenberg SM, Vincent J, et al. Vasopressor and inotropic support in septic shock: An evidence-based review. Crit Care Med 2004;32(S11):S455-65.

43. Hollenberg SM, Ahrens TS, Annane D, et al. Practice parameters for hemodynamic support of sepsis in adult patients: 2004 update. Crit Care Med 2004;32(9):1928-48.

44. Ihle BU. Clinical practice guidelines for improving outcomes in sepsis. Heart, Lung and Circ 2008;17(S4):S26-S31.

45. Robinson, A. What's the best vasopressor in septic shock? Emerg Med 7 2010;27(7):556-8.

46. Dellinger RP, Levy MM, Rhodes A, et al. Surviving sepsis campaign: International guidelines for management of severe sepsis and septic shock: 2012. Crit Care Med 2013; 41(2):580-637.

47. Patel GP, Grahe JS, Sperry M, et al. Efficacy and safety of dopamine versus norepinephrine in the management of septic shock. Shock 2010;33(4):375-80.

48. Povoa PR, Carneiro AH, Ribeiro OS, et al. Influence of vasopressor agent in septic shock mortality. Results from the Portuguese community-acquired sepsis study (SACiUCI study). Crit Care Med 2009;37(2):410-6.

49. Boulain T, Runge I, Bercault N, et al. Dopamine therapy in septic shock: Detrimental effect on survival? 7 of Crit Care 2009;24(4):575-82.

50. $\mathrm{Xu} \mathrm{B,} \mathrm{Oziemski} \mathrm{P.} \mathrm{Dopamine} \mathrm{versus} \mathrm{noradrenaline} \mathrm{in}$ septic shock. Australasian Med 7 2011;4(10):571-4.

51. Seguin P, Bellissant E, Le Tulzo Y, et al. Effects of epinephrine compared with the combination of dobutamine and norepinephrine on gastric perfusion in septic shock. Clin Pharma and Therapeutics 2002;71(5):381-8.

52. Levy B, Bollaert PE, Charpentier C, et al. Comparison of norepinephrine and dobutamine to epinephrine for hemodynamics, lactate metabolism, and gastric tonometric variables in septic shock: a prospective, randomized study. Intensive Care Med 1997;23(3):282-7.

53. Annane D, Vignon P, Renault A, et al. Norepinephrine plus dobutamine versus epinephrine alone for management of septic shock: A randomised trial. Lancet 2007;370(9588):676-84.
54. Mahmoud K, Ammar A. Norepinephrine supplemented with dobutamine or epinephrine for the cardiovascular support of patients with septic shock. Indian 7 of Crit Care Med 2012;16(2):75-80.

55. Jain G, Singh DK. Comparison of phenylephrine and norepinephrine in the management of dopamine-resistant septic shock. Indian 7 of Crit Care Med 2010;14(1):29-34.

56. Morelli A, Ertmer C, Rehberg S, et al. Phenylephrine versus norepinephrine for initial hemodynamic support of patients with septic shock: a randomized, control trial. Crit Care 2008;12(6):R143.

57. Morelli A, Lange M, Ertmer C, et al. Short-term effects of phenylephrine on systemic and regional hemodynamics in patients with septic shock: a crossover pilot study. Shock 2008;29(4):446-51.

58. Thiele RH, Nemergut EC, Lynch C. The clinical implications of isolated alphal adrenergic stimulation. Anesthesia \& Analgesia 2011;113(2):297-304.

59. Lauzier F, Levy B, Lamarre P, et al. Vasopressin or norepinephrine in early hyperdynamic septic shock: A randomized clinical trial. Intensive Care Med 2006;32(11):1782-9.

60. Luckner G, Dunser MW, Jochberger S, et al. Arginine vasopressin in 316 patients with advanced vasodilatory shock. Crit Care Med 2005;33(11):2659-66.

61. Russell JA, Walley KR, Singer J, et al. Vasopressin versus norepinephrine infusion in patients with septic shock. New Engl 7 Med 2008;358(9):877-87.

62. Oliveira S. Early vasopressin application in shock. Crit Care. Conference: Sepsis 2011 Beijing, China. Conference Start: 20111026. Conference End: 20111028. Conference Publication 2011: (Var.Pagings), 15 S2.

63. Lam S, Bauer S. Association between catecholamine dose at the onset of arginine vasopressin for septic shock and intensive care unit mortality. CritCare Med. Conference: 39th Critical Care Congress of the Society of Critical Care Medicine, Miami Beach, FL, United States. Conference Start: 20100109. Conference End: 20100113. Conference Publication: (Var.Pagings), 37(S12), A243.

64. Andresen M, Dougnac A, Diaz O, et al. Use of methylene blue in patients with refractory septic shock: Impact on hemodynamics and gas exchange. 7 of Crit Care 1998; 13(4):164-8.

65. Kirov MY, Evgenov OV, Evgenov NV, et al. Infusion of methylene blue in human septic shock: a pilot, randomized, controlled study. Crit Care Med 2001;29(10):1860-7.

66. Paciullo CA, Horner DM, Hatton K, et al. Methylene blue for the treatment of septic shock. Pharmacotherapy 2010; 30(7):702-15.

67. Kwok E, Howes D. Use of methylene blue in sepsis: A systematic review. 7 of Intensive Care Med 2006;21(6):359-63.

68. Wilkman E, Kaukonen M, Pettila V, et al. The association between inotrope treatment and 90-day mortality in patients with septic shock. Intensive Care Med. Conference: 24th Annual Congress of the European Society of Intensive Care Medicine, ESICM LIVES 2011 Berlin, Germany. Conference Start: 20111001. Conference End: 20111005. Conference Publication: (Var.Pagings), 37, S146.

69. Vincent J, Roman A, Kahn RJ. Dobutamine administration in septic shock: Addition to a standard protocol. Crit Care Med 1990;18(7):689-93. 
70. Hai-Bo Q, Yi Y, Shao-Xia Z, et al. Renal effect of dopamine, norepinephrine, epinephrine, or norepinephrine-dobutamine in septic shock. Crit Care and Shock 2002;5(1):9-14.

71. De Backer D, Creteur J, Dubois M, et al. The effects of dobutamine on microcirculatory alterations in patients with septic shock are independent of its systemic effects. Crit Care Med 2006;34(2):403-8.

72. Enrico C, Kanoore Edul V, Vazquez AR, et al. Systemic and microcirculatory effects of dobutamine in patients with septic shock. 7 of Crit Care 2012;27(6):630-8.

73. Hernandez G, Regueira T, Bruhn A, et al. Effects of dobutamine on microcirculation, regional and peripheral perfusion in septic shock patients: A randomized double blind crossover trial. Preliminary report. Intensive Care Med. Conference: 24th Annual Congress of the European Society of Intensive Care Medicine, ESICM LIVES 2011 Berlin, Germany. Conference Start: 20111001. Conference End: 20111005. Conference Publication: (Var.Pagings), 37, S92.

74. Rivers E, Nguyen B, Havstad S, et al. Early goal-directed therapy in the treatment of severe sepsis and septic shock. N Engl 7 Med 2001;345(19):1368-77.

75. Ploumis A, Yadlapalli N, Fehlings MG, et al. A systematic review of the evidence supporting a role for vasopressor support in acute SCI. Spinal Cord 2010;48(5):356-62.

76. Auzinger $\mathrm{G}$, Wendon J. Intensive care management of acute liver failure. Current Opinion Crit Care 2008;14(2):179-88.

77. Gines P, Fernandez J, Durand F, Saliba F. Management of critically ill cirrhotic patients. $\mathcal{F}$ of Hepatology 2012; 56(S1):S13-S24.

78. Jalan R. Acute liver failure: current management and future prospects. 7 of Hepatology 2005;42:S115-23.

79. Lee W, Larson A, Stravitz T. AASLD Position Paper: The Management of Acute Liver Failure: Update 2011. Нepatology 2011;54(3):1-22.

80. Larson AM, (2011). Acute Liver Failure, in Schiff's Diseases of the Liver, 11th Ed. (eds ER Schiff, WC Maddrey, MF Sorrell), Wiley-Blackwell, Oxford, UK. doi: 10.1002/ 9781119950509.ch19.

81. Rinella ME, Sanyal A. Intensive management of hepatic failure. Semin Respir Crit Care Med 2006;27(3):241-61.

82. Patton J, Misel M, Gish RG. Acute liver failure in adults: an evidence-based management protocol for clinicians. Gastroenterol Hepatol 2012;8(3):161-212.

83. Stravitz RT, Kramer AH, Davern T, et al. Intensive care of patients with acute liver failure: recommendations of the US Acute Liver Failure Study Group. Crit Care Med 2007; 35(11):2498-508.

84. Olson JC, Wendon JA, Kramer DJ, et al. Intensive care of the patient with cirrhosis. Hepatology 2011;54(5):1864-72.

85. Wagener G, Kovalevskaya G, Minhaz M, et al. Vasopressin deficiency and vasodilatory state in end-stage liver disease. 7 Cardiothorac Vasc Anesth 2011;25(4):665-70.

86. Sheikh A, Shehata YA, Brown G, et al. Adrenaline (epinephrine) for the treatment of anaphylaxis with and without shock. Cochrane Database of Systematic Reviews 2012,4.

87. Brown S, Blackman K, Stenlake V, et al. Insect sting anaphylaxis; prospective evaluation of treatment with intravenous adrenaline and volume resuscitation. Emerg Med 7 2004;21(2):149-54.
88. Dewachter P, Jouan-Hureaux V, Lartaud I, et al. Comparison of arginine vasopressin, terlipressin, or epinephrine to correct hypotension in a model of anaphylactic shock in anesthetized brown norway rats. Anesthesiology 2006;104(4):734-41.

89. Dewachter P, Raeth-Fries I, Jouan-Hureaux V, et al. A comparison of epinephrine only, arginine vasopressin only, and epinephrine followed by arginine vasopressin on the survival rate in a rat model of anaphylactic shock. Anesthesiology 2007;106(5):977-83.

90. Zheng F, Barthel G, Chantal M, et al. Methylene blue and epinephrine, a synergistic association for anaphylactic shock treatment in anesthetized brown norway rats. Euro fof Anaesthesiology. Conference: European Anaesthesiology Congress, EUROANAESTHESIA 2011 Amsterdam Netherlands. Conference Start: 20110611. Conference End: 20110614. Conference Publication: (Var.Pagings), 28, 192.

91. Hebard S, Ball AJ. Role of alpha agonists in treating anaphylaxis. BM7 2008;337(7661):67.

92. Heytman M, Rainbird A. Use of alpha-agonists for management of anaphylaxis occurring under anaesthesia: Case studies and review. Anaesthesia 2004;59(12):1210-5.

93. Hussain AM, Yousuf B, Khan MA, et al. Vasopressin for the management of catecholamine-resistant anaphylactic shock. Singapore Med 7 2008;49(9):e225-8.

94. Evora PR, Roselino C, Schiaveto PM. Methylene blue in anaphylactic shock. AnnEmerg Med 1997;30(2):240.

95. Meng L, Williams EL. Case report: Treatment of rocuronium-induced anaphylactic shock with vasopressin. Can $\mathcal{Z}$ of Anesthesia 2008;55(7):437-40.

96. Ponniah M, Saravanan PA, Jeslin L, et al. Role of norepinephrine in anaphylaxis. $\mathcal{F}$ of Anaesthesiology Clin Pharma 2009;25(2):244-5.

97. Oliveira N, Duarte NM, Vicente WV, et al. Methylene blue: an effective treatment for contrast medium-induced anaphylaxis. Med Sci Monit 2003;9(11):CS102-6.

98. Schummer C, Wirsing M, Schummer W. The pivotal role of vasopressin in refractory anaphylactic shock. Anesthesia \& Analgesia 2008;107(2):620-4.

99. Schummer W, Schummer C, Wippermann J, et al. Anaphylactic shock: is vasopressin the drug of choice? Anesthesiology 2004;101(4):1025-7.

100. Stocche R, Garcia LV, Paulino Dos Reis M, et al. Methylene blue to treat anaphylaxis during anesthesia: case report. Revista Brasileira de Anestesiologia 2004;54 (6):809-14.

101. Williams S, Denault A, Pellerin R. Vasopressin for treatment of shock following aprotinin administration. Can 7 of Anesthesia 2004;51(2):169-72.

102. Part 10.6 : Anaphylaxis. Circulation 2005;112(24 S):143-5.

103. Brown S. The pathophysiology of shock in anaphylaxis. Immuno and Allergy Clinics of N Am 2007;27(2):165-75.

104. Kemp S, Lockey R, Simons F. Epinephrine: The drug of choice for anaphylaxis. A statement of the world allergy organization. Allergy 2008;63(8):1061-70.

105. Lieberman P, Nicklas R, Oppenheimer J, et al. The diagnosis and management of anaphylaxis practice parameter: 2010 update [Abstract]. The $\mathcal{f}$ of Allergy and Clin Imтипо 2010;126(3):477-80.e42. 
106. Simons F, Ardusso L, Bilo M, et al. World Allergy Organization. World allergy organization anaphylaxis guidelines: summary. The $\mathfrak{f}$ of Allergy and ClinImmuno 2011; 127(3):587-93.

107. Soar J, Perkins G, Abbas G, et al. European resuscitation council guidelines for resuscitation 2010 Section 8. Cardiac arrest in special circumstances: electrolyte abnormalities, poisoning, drowning, accidental hypothermia, hyperthermia, asthma, anaphylaxis, cardiac surgery, trauma, pregnancy, electrocution. Resuscitation 2010;81(10):1400-33.

108. Matsumoto S, Hagiwara S, Kusaka R, et al. Catecholamine-resistant shock and hypoglycaemic coma after cardiotomy in a patient with unexpected isolated ACTH deficiency. 7 Anesth 2011;25(3):431-4.

109. Picolos MK, Nooka A, Davis AB, et al. Bilateral adrenal hemorrhage: an overlooked cause of hypotension. 7 Emerg Med 2007:Feb 32(2):167-9.

110. Serrano N, Jimenez JJ, Brouard MT, et al. Acute adrenal insufficiency after cardiac surgery. Crit Care Med 2000; 28(2):569-70.

111. Bunker N, Higgins D. Peripheral administration of vasopressin for catecholamine-resistant hypotension complicated by skin necrosis. Crit Care Med 2006;34(3):935; author reply 935-6, doi: 10.1097/01.CCM.0000202202.85087.37.

112. Putland M, Kerr D, Kelly AM. Adverse events associated with the use of intravenous epinephrine in emergency department patients presenting with severe asthma. Ann Emerg Med 2006;47(6):559-63. doi: 10.1016/j.anne mergmed.2006.01.022.

113. Tran DQ, Finlayson RJ. Use of stellate ganglion block to salvage an ischemic hand caused by the extravasation of vasopressors. Reg Anesth Pain Med 2005;30(4):405-8.

114. Davies AG, Russell WC, Thompson JP. Extravasation and tissue necrosis secondary to central line infusions. Anaesthesia 2003;58(8):820-1.

115. Kahn JM, Kress JP, Hall JB. Skin necrosis after extravasation of low-dose vasopressin administered for septic shock. Crit Care Med 2002;30(8):1899-901.

116. Stier PA, Bogner MP, Webster K, et al. Use of subcutaneous terbutaline to reverse peripheral ischemia. Am $\mathcal{Z}$ Emerg Med 1999;17(1):91-4.

117. Chen JL, O'Shea M. Extravasation injury associated with low-dose dopamine. Ann Pharmacother 1998;32(5):545-8.

118. Perrot J, Eyraud P, Guy C, et al. Terlipressin-induced mucocutaneous skin necrosis: Report of four cases. Eur $\mathcal{Z}$ Dermatol 1996;6(1):14-18.

119. Cooper BE. High-dose phentolamine for extravasation of pressors. Clin Pharm 1989;8(10):689.

120. Reed WP, Newman KA, Applefeld MM, et al. Drug extravasation as a complication of venous access ports. Ann Intern Med 1985;102(6):788-90.

121. Anderson JR, Johnston GW. Development of cutaneous gangrene during continuous peripheral infusion of vasopressin. Br Med 7 (Clin Res Ed) 1983;287(6406):1657-8.

122. Wormser GP, Kornblee LV, Gottfried EB. Cutaneous necrosis following peripheral intravenous vasopressin therapy. Cutis 1982;29(3):249-52.

123. Crocker MC. Intravascular guanethidine in the treatment of extravasated vasopressin. $N$ Engl 7 Med 1981;304(23):1430.
124. Mogan GR, Wormser GP, Gottfried EB. Infected gangrene. A serious complication of peripheral vasopressin administration. Am 7 Gastroenterol 1980;73(5):426-9.

125. Hoff JV, Beatty PA, Wade JL. Dermal necrosis from dobutamine. N Engl 7 Med 1979;300(22):1280.

126. Lynch DJ, Key JC, White RR. 4th. Management and prevention of infiltration and extravasation injury. SurgClin North Am 1979;59(5):939-49.

127. Upton J, Mulliken JB, Murray JE. Major intravenous extravasation injuries. Am 7 Surg 1979;137(4):497-506.

128. Gaze NR. Tissue necrosis caused by commonly used intravenous infusions. Lancet 1978;2(8086):417-9.

129. Greenwald RA, Rheingold OJ, Chiprut RO, et al. Local gangrene: A complication of peripheral pitressin therapy for bleeding esophageal varices. Gastroenterology 1978;74(4):744-6.

130. Boltax RS, Dineen JP, Scarpa FJ. Gangrene resulting from infiltrated dopamine solution. $N$ Engl $f$ Med 1977; 296(14):823.

131. Ebels T, van der Heide JN. Dopamine-induced ischaemia. Lancet 1977;2(8041):762.

132. Stetson JB, Reading GP. Avoidance of vascular complications associated with the use of dopamine. Can Anaesth Soc f 1977;24(6):727-33.

133. Oglesby JE, Baugh JH. Tissue necrosis due to norepinephrine. Am $\mathcal{F}$ Surg 1968;115(3):408-12.

134. Weeks PM. Ischemia of the hand secondary to levarterenolbitartrate extravasation. methods of management. 7AMA 1966;196(3):288-90.

135. Fritz H, Hagstam KE, Lindqvist B. Local skin necrosis after intravenous infusion of norepinephrine, and the concept of endotoxinaemia. A clinical study on 10 cases. Acta Med Scand 1965;178(4):403-16.

136. Jaconelli J. Massive gangrene of the lower limb following use of continuous noradrenaline intravenous infusion. Med 7 Aust 1965;1(3):79-80.

137. Grewal RS. Gangrene following infusion of norepinephrine. report of a case. 7 Int Coll Surg 1964;41:275-7.

138. Mitchinson MJ, Gresham GA. Epidermal necrosis due to nor-adrenaline. Br 7 Dermatol 1964;76:495-6.

139. Mehrotra MP, Kishore B. Local tissue necrosis and cutaneous gangrene following intravenous infusion of noradrenaline. 7 Assoc Physicians India 1963;11:639-43.

140. Zucker G, Eisinger RP, Floch MH, et al. Treatment of shock and prevention of ischemic necrosis with levarterenol-phentolamine mixtures. Circulation 1960; 22:935-7.

141. Close AS, Frackelton WH. Cutaneous necrosis due to norepinephrine: Analysis of reported cases and surgical treatment. Wis Med 7 1958;57(3).

142. Bryant MF, Berben JY, Howard JM. Prevention of norepinephrine (levophed) sloughs. 7 Med Assoc Ga 1957; 46(7):336-9.

143. De Alvarez RR, Nyhus LM, Merendino KA, et al. Tissue necrosis associated with intravenous nor-epinephrine administration. Am Surg 1957;23(7):619-35.

144. Hardy SB, Hamilton JM. Treatment of tissue necrosis following intravenous use of norepinephrine. Plast and Reconstr Surg 1957 (1946);20(5):360-5. 
145. Heard GE. Skin necrosis in nor-adrenaline therapy. $B r f$ Clin Pract 1957;11(4):260-2.

146. Pelner L. Treatment of localischemia due to levarterenol (levophed) leakage with piperoxan. $7 \mathrm{Am}$ Med Assoc 1957;165(5):444-7.

147. Zucker G. Use of phentolamine to prevent necrosis due to levarterenol. 7 Am Med Assoc 1957;163(16):1477-9.

148. McGinn JT, Schluger J. Skin sloughs associated with levophed; pathogenesis, prevention and treatment. $A m 7$ Surg 1956;92(4):594-602.

149. Perlow S, Shapiro RA. Skin necrosis following intravenous use of norepinephrine; report of six cases. Am 7 Surg 1956;92(4):566-70.

150. Selke O Jr. Histamine iontophoresis to prevent tissue necrosis following levarterenol extravasation. Arch Phys Med Rebabil 1956;37(10):643-6.

151. Wall CA, Hanlon CR. Necrosis following administration of levarterenol during shock. AMA Arch Surg 1956;72 (2):332-5.

152. Hall B. Recovery of patient in prolonged shock after arterenoltherapy. 7 Am Med Assoc 1955;157(8):653-4.

153. Hardie GH, Hunter DC. Skin necrosis with the intravenous use of norepinephrine. Med Bull (Ann Arbor) 1955; 21(7):213-9.

154. Humphreys J, Johnston JH, Richardson JC. Skin necrosis following intravenous noradrenaline. $\mathrm{Br}$ Med $\mathcal{F}$ 1955; 2(4950):1250-2.

155. Irvin CWJ, Bunch GH. Spontaneous rupture of the esophagus, with a note on tissue necrosis from nor-epinephrine. Am 7 Med 1954;17(4):571-7.
156. Kepes ER, Haimovichi H, Simon B. Skin necrosis following intravenous use of norepinephrine; case reports. Surgery 1954;36(4):822-5.

157. Peirce E, Polley VB. Necrosis following intravenous use of neo-synephrine. $N$ Engl 7 Med 1954;250(3):114-5. doi: 10.1056/NEJM195401212500305.

158. Bergmann H. Advantages and disadvantages of prolonged use of nor-epinephrine. Int 7 Anesth 1953;1(1):29-34.

159. Crawford ES, Haynes BW. The use of nor-epinephrine in the treatment of hypotension associated with common surgical conditions. Am Surg 1953;19(2):191-201.

160. Uricchio JF, Calenda DG, Cutts FB. Ulceration on the skin following intravenous use of arterenol. $7 \mathrm{Am} \mathrm{Med} \mathrm{Assoc}$ 1953;152(7):607-8.

161. Greenwald HP, Gootnick A, Luger NM, et al. Tissue necrosis following subcutaneous infiltration with norepinephrine; report of two cases. $N$ Engl 7 Med 1952, 246(7):252-3. doi: 10.1056/NEJM195202142460704.

162. Kurland GS, Malach $M$. The clinical use of norepinephrine in the treatment of shock accompanying myocardial infarction and other conditions. N Engl 7 Med 1952;247(11):383-9. doi: 10.1056/NEJM195209112471102.

163. Moen TC, Sarwark JF. Compartment syndrome following intraosseousinfusion. Orthopedics 2008;31(8):815.

164. Wechselberger G, Radauer W, Schimpl G, et al. Lower limb salvage in a 7-month-old infant using free tissue transfer. 7 Pediatr Surg 2011;46(9):1852-4. doi: 10.1016/j. jpedsurg.2011.06.037.

165. Stoll E, Golej J, Burda G, et al. Osteomyelitis at the injection site of adrenalin through an intraosseous needle in a 3-month-old infant. Resuscitation 2002;53(3):315-8. 